\title{
14 \\ COLLECTIVE INACTION AND COLLECTIVE EPISTEMIC AGENCY
}

\author{
Michael D. Doan
}

\subsection{Responsibility for Collective Inaction: The Seinfeld Paradigm}

Why would we want to help somebody? That's what nuns and Red Cross workers are for!

George Costanza ("The Finale” 1998)

Twenty years after it aired to an audience of 76 million, the final episode of Seinfeld still looms large in the popular imagination. For philosophers interested in the idea of collective responsibility, it was also among the most memorable thought experiments in television history. While it seems unlikely that Larry David was cribbing philosophical perspectives on responsibility for collective inaction when he wrote the script for "The Finale," the episode does employ a particularly influential insight of Virginia Held's. According to Held, even a "random collection" of individuals ${ }^{1}$ can sometimes be held morally responsible for not acting collectively, or else for not organizing themselves into a group capable of so doing (Held 1970). Considered as a thought experiment, "The Finale" invites us to imagine: What would happen if Held's insight were codified into law? How would a judge hold us accountable for failing to join forces and act together when nothing less would have sufficed to prevent harm?

Here is how the thought experiment unfolds: the scene of the crime is Latham, Massachusetts (Jerry, the New Yorker, calls it "Sticksville"). Jerry and friends are hanging out on a street corner-joking around about nothing, as usual. Across the street, and in full view and hearing of the four, a carjacker pulls an overweight man named Howie out of his car, robs him at gunpoint, and flees the scene in his vehicle. Kramer stands by, filming the entire incident on his camcorder. Meanwhile, Jerry, Elaine, and George crack sarcastic, fat-shaming jokes at Howie's expense. Howie, who could see that the four did nothing whatsoever to come to his aid, relays his plight to Matt Vogel, the reporting police officer. Vogel immediately puts the four under arrest, citing Article 223-7 of the Latham County Penal Code. Elaine protests, "What? No, no-we didn't do anything!'Vogel replies, "That's exactly right. The law requires you to help or assist anyone in danger so long as it's reasonable to do so." George complains, "I've never heard of that." Responds Vogel, "It's new—it's called the Good Samaritan Law" ("The Finale" 1998).

In fact, several European countries and ten U.S. states had similar laws on the books by the time the curtains closed on Seinfeld in 1998. These laws tend to include criteria similar to those 
proposed by Held, who holds that a random collection can only be held responsible for their inaction "when the action called for in a given situation is obvious to the reasonable person and when the expected outcome of the action is clearly favorable" (Held 1970: 476). According to what in the U.S. are called "duty to rescue" or "Good Samaritan" laws, the penalties for failing to come to another's aid are typically minor. In "The Finale," though, they are much stiffer: the local law calls for a maximum fine of $\$ 85,000$ and as much as five years in prison. As the episode unfolds, the defendants in the controversial "Good Samaritan Trial" (the aptly named "New York Four") are ultimately found guilty of criminal indifference and sentenced to a year in prison. The upshot of the thought experiment is clear: pace Jackie Chiles, defense lawyer extraordinaire, there surely is such a thing as a "guilty bystander," and such bystanders can and will be made to pay for their crimes of omission ("The Finale" 1998).

I'm struck by how frequently "The Finale" comes up in discussions of responsibility for collective inaction. Incidentally, most philosophers working on the topic make use of a handful of thought experiments that conform to what I have come to call "the Seinfeld paradigm." In these relatively simple "coordinated bystander cases" (Isaacs 2011: 143), a particular harm (say, a carjacking) cannot be prevented through the isolated, uncoordinated actions of individuals, but only through a collective action undertaken by an as of yet unformed organized group (say, by Jerry, Elaine, George, and Kramer joining forces to scare off a gunman). Next to Held's bystanders to a strangling case (Held 1970), there is Larry May's bystanders to a drowning child case (May 1990); David Copp's bystanders to homelessness case (Copp 1991); Torbjörn Tännsjö’s bystanders to pushing a car up a hill case (Tännsjö 2007); and Tracy Isaacs' bystanders to a river rafting disaster case (Isaacs 2011), to name a few of the most memorable variations (see also Petersson 2008). These cases share the following key features: first, the victims are always depicted as totally helpless, while the protagonists are cast as completely innocent "bystanders" - that is, they are not directly implicated in or affected by the problem prior to their alleged failure to intervene. Second, the problems can always be solved by a single collective action, even when several collective action solutions are available. Third, the risks of taking the required course of action are always minor, whereas success is assured. Since the problems have no systemic dimensions, the prospect of solving them never threatens the statuses, identities, or ways of life of anyone involved. Indeed, most of these cases have been designed to be even more clear cut than that of the New York Four, whose reluctance to confront a gunman is at least understandable.

Following Held's lead, each of the above-mentioned philosophers makes use of similarlystructured thought experiments in the course of arguing that a random collection can sometimes be blamed for failing to act collectively. However, Isaacs has recently broadened the focus of conversation by asking: what do these accounts suggest are our present responsibilities with respect to some of the most urgent and complex problems of our time, such as climate change, ecological degradation, and global poverty? Although there has been some disagreement about when it makes sense to say that a random collection could have done otherwise, and over how responsibility ought to be distributed when such a group has failed to act, there has also been considerable agreement both methodologically and substantively. Each philosopher agrees that we ought to employ some version of the reasonable person standard ${ }^{2}$ when determining whether a group has failed to act or has an obligation to act now. And although each stops short of drawing out the legal implications of their views, they generally agree that blame is a morally appropriate response in many instances of collective inaction, even those involving merely "putative" or "loosely structured groups" (May 1990: 270).

In this chapter I consider the costs of this striking convergence in methodology. I wonder: What questions about collective responsibility cannot be asked when the focus of inquiry is narrowed 
to cases fitting the Seinfeld mold? I argue that the use of fictional thought experiments in philosophical analyses of collectively responsibility unhelpfully constrains our thinking, precisely in those places where it needs to be at its most generative. While there are many possible avenues of criticism here, ${ }^{3}$ I focus on how the received way of thinking about responsibility for collective inaction ignores and renders irrelevant the epistemic agency and creativity of ordinary people ${ }^{4}$ while excluding from consideration a range of problems that clearly call for coordinated responses, yet have no obvious, readymade solutions. What is needed, I propose, is not a different, more nuanced set of thought experiments, but an altogether different approach to thinking about responsibility for collective inaction. In the course of exploring a concrete case of collective brilliance in action, I suggest that the production of new questions, ideas, and knowledge in and through collective struggle ought to be at the very center of future inquiry. ${ }^{5}$

The remainder of this chapter proceeds in two parts. First, I offer a critique of the received way of thinking about responsibility for collective inaction. Second, I propose an alternative approach that takes as its point of departure the epistemic agency exhibited by people navigating impossible situations together. One such situation is becoming increasingly common in the context of climate change, particularly in coastal regions: so-called "natural" disasters, such as hurricanes and superstorms, wreaking havoc on communities-flooding homes, collapsing infrastructures, and straining the capacities of existing organizations to safeguard lives and livelihoods. What happens when philosophical reflection begins here - in places where the institutions and practices that have emerged over the last century seem incapable of addressing the problems communities face now, ${ }^{6}$ and where people find themselves turning to one another for the sake of their own survival?

\subsection{Breaking Free of the Seinfeld Paradigm}

Why should philosophers break free of what I have called "the Seinfeld paradigm"? In this section, I explore the pitfalls of basing our accounts of collective responsibility on analyses of cases fitting the Seinfeld mold. I begin with a brief review of Held's influential account of responsibility for collective inaction. Next, I consider what we inevitably miss when our focus is narrowed to fictional thought experiments of this type.

Recall that, on Held's account, a random collection of individuals can only be held responsible for failing to act collectively "when the action called for in a given situation is obvious to the reasonable person and when the expected outcome of the action is clearly favorable" (Held 1970: 476). Writing in 1970, Held anticipates much future conversation when she remarks, in passing, on the possible implications of her view for "political situations":

If a reasonable person judges that the overthrow of an existing political system is an action that is obviously called for, he may perhaps consider himself morally responsible for the failure of the random collection of which he is a member to perform this action. If he thinks some action to change an existing political system is obviously called for, but is not clear about which action, he may consider himself morally responsible for the failure of the random collection of which he is a member to perform the quite different action of transforming itself into a group capable of arriving at decisions on such questions.

A provocative example, to be sure. Revolutionary fervor aside, though, Held seems to be making a bid for theoretical simplicity and parsimony here. Having based her account on an analysis of a 
handful of relatively simple coordinated bystander cases, she seems to be suggesting that we can simply scale up to far more complex situations from there. Perhaps, then, we need rely on only a single set of tools when grappling with collective action problems of all sorts.

Held's gambit has more recently been taken up by Tracy Isaacs. Whereas Held starts with a case involving a strangler on the subway, Isaacs draws our attention to a group of children rafting down a river (Isaacs 2011: 243). Suddenly caught in rapids, hurtling helplessly toward a waterfall, the children will surely be killed if a random collection of onlookers does not join forces to intervene. Isaacs utilizes this thought experiment to argue that even a group of complete strangers can presently have a collective obligation to come to the aid of others, at least in situations where there is "a clear map between the situation, the required course of [collective] action and a collective agent" (ibid. 143). Scaling up to the question of what our current responsibilities are with respect to such complex problems as climate change, Isaacs argues that the members of a loosely structured group are collectively responsible for coming together and acting when - and only when - a collective action solution has, as she puts it, "come into focus" (ibid. 152). Harking back to Held's passing remarks, Isaacs suggests that the collective obligation to implement a given solution "exists in virtue of the clarity, by the standard of the reasonable person, of the collective action required" (ibid. 148). Hence, "Where there is a lack of clarity at the collective level, what is lacking is a clear picture of what collective course of action would effectively address the moral concern" (ibid.).

How often is this knowledge condition met? ${ }^{7}$ I suspect it is met only rarely, in relation to a very specific set of problems. To see this, consider a revised version of Larry David's thought experiment. I call it “The Inverted Finale" because it features a case lacking all the distinguishing features of the Seinfeld paradigm. ${ }^{8}$ My version invites us to imagine: What would happen if Held's knowledge condition were incorporated into our practices of holding ourselves and others accountable? Whose collective inaction would be excused and, with time, taken for granted?

Here is how the revised thought experiment unfolds: Jerry and friends are hanging out in front of a Manhattan diner. On a daily basis, and in full view and hearing of one another, they have each been participating in a variety of social practices that rely on energy-intensive, fossil-fuel dependent cycles of extraction, production, consumption, and waste (e.g., eating animal products, heating and cooling their spacious apartments, commuting in cars, and more). Although each of the four aims to cause as little suffering and death as possible, they know they are deeply implicated in situations they repudiate. Simply by living, eating, and throwing things away in a major U.S. city, they are caught up in broader systemic processes which they know are causing significant, ongoing harms to ecosystems and lives both near and far, and which are clearly unsustainable in the long run. They are aware of the many ways they benefit from the oppression of others and are also deeply damaged by the interlocking systems they play a role, however small, in reproducing. They understand that they, too, are being killed by those systems, however much more softly - that they, too, are neither the totally helpless "victims" of systemic outcomes, nor are they merely "standing by," unaffected and affecting none. Given their collective involvement in the ecological and social problems that keep them awake at night, they could hardly consider themselves "inactive." Simply by going with the flow, they are actively sustaining what they know to be unsustainable.

Noticing the weary expressions on his friends' faces, Kramer captures the moment on his camcorder. Meanwhile, Jerry, Elaine, and George crack self-deprecating jokes, debating who would be the first to be killed on The Walking Dead. Newman, Jerry's mail carrier, is every bit as aware as the others that his attempts at "ethical consumption" make little difference. He, too, has come to realize that there is no single, definitive collective action participation in which they could "solve" their shared predicament. Joining organized, long-term efforts to bring about 
systemic change would require significant commitment and could also involve a measure of risk and sacrifice. Even so, Newman feels frustrated that the New York Four are telling jokes while the world burns - frustrated enough to share his plight with a cop walking the beat. Confused, the cop looks Newman square in the eye: "What do you mean, 'they aren't doing anything'? Aren't doing what, exactly? Talk to me when you've got a clear solution, wise ass." The upshot is clear: pace Held, Isaacs, and others, it is highly doubtful that we can simply scale up from the cases on which they focus, to the far more complex situations, such as climate change and global poverty, that they also claim to be offering resources for addressing.

Two lines of response are available here. First of all, those who remain sympathetic to the received way of thinking about responsibility for collective inaction might reject my description of the New York Four's predicament. In place of "The Inverted Finale," they might generate another thought experiment that makes Jerry's relationship to climate change seem a lot more like his relationship to a carjacking (the victims would be elsewhere, completely powerless; there would be no systemic dimensions to the problem; Jerry and friends would somehow be standing by, innocently, with no stake in the situation; and so forth). This would show that the types of problems I claim fall outside of the Seinfeld paradigm can be made to fit—or, at least, that specific aspects of those problems can be ignored for simplicity's sake. In that case, perhaps the New York Four are not off the hook for their collective inaction after all.

I find this response deeply unsatisfying. For one, I take it that an account of collective responsibility will only be useful to the extent that it helps us deal with the full range of problems that call for coordinated responses. Problems superficially, inaccurately, or otherwise falsely described, cannot be collectively dealt with, so our accounts need to approach the characterization of situations in an empirically rigorous way. Given that my description of the New York Four's predicament accurately captures some of its more salient features, and also seems applicable to several systemic problems other than those mentioned here, it stands to reason that situations of these types cannot be forced to fit the Seinfeld mold without considerable distortion. Unless it can be shown that situations with these features either do not or could not arise or are so rare as to be unworthy of mention, it will be difficult to find promise in the received approach.

Second, those still determined to take up Held's gambit might simply bite the bullet. They could accept that there is nothing strange about the cop's readiness to excuse the New York Four, insisting instead that it is Newman's frustration that cries out for justification. After all, there has to be a limit to the situations that a loosely structured group can be held morally responsible for failing to address, and it makes sense to draw the line at cases where there is no clear picture of what collective action would effectively address the concern. If the boundaries of collective responsibility ought to be drawn elsewhere, then a case to that effect needs to be made. Otherwise we are just trading intuitions and are unlikely to get very far.

This response fares no better. As I point out elsewhere (Doan 2016), the burden of proof lies with those who favor Held's knowledge condition, for that condition expresses a substantive view about the circumstances under which we should see ourselves and others as sharing responsibility for working together to address impending crises and catastrophes, not to mention many already present disasters. Yet it is hardly self-evident and has yet to be defended. So, an argument is owed in defense of the above-mentioned presumptions about the bounded nature of collective responsibility, and about the precise location of those boundaries.

It may make sense to draw a boundary in the place Held proposes. But I suspect that is only if we have already joined her in adopting a peculiarly juridical frame of mind. Although Held is concerned with questions of moral responsibility, she does invite us to consider such questions from the peculiar vantage of a judge or juror, reducing collective responsibility to collective liability and relying on a legal fiction for the sake of adjudication. But I doubt that we need to 
think like a state official to hold ourselves and others accountable for what we collectively fail to do (see Doan 2016; Young 2011). If adopting a juridical approach means we can no longer have meaningful conversations about our shared responsibility for addressing seemingly intractable systemic problems, then that is an approach to be avoided, not embraced.

Furthermore, I take it that part of the point of the practice of holding ourselves and others accountable for our collective inaction is to encourage each other to come together, get organized, and do what is required of us to reduce the amount of harm and injustice in the world. If we can only justifiably hold one another accountable when a clear solution has already "come into focus," then what are we to do about those problems that have no obvious, readymade solutions? How are we to handle those situations where it would be flatly unreasonable to expect the emergence of a single collective action that is perfectly "clear" to and "clearly favorable" for all involved? What about those situations where the people and institutions we have grown accustomed to looking to for answers either have none to share, or none at all? Here the received view is curiously silent.

Whereas it may seem inconsequential to draw a line around those situations we are already equipped to address with considerable confidence, the problems that make the New York Four weary are not so easily dismissed. Of course, the interrelated problems of climate change, ecological degradation, and global poverty do not suddenly resolve themselves when the cop refuses to make an arrest. Under these circumstances, what relief is there in saying to one another, "Well, at least we're off the hook"? Unless we find meaningful ways to hold ourselves and others accountable for coming together to address especially challenging problems in spite of our shared not knowing how to go on, we will be left without a valuable tool for protecting what matters.

In summary, the received approach to thinking about responsibility for collective inaction excludes from consideration a range of ecological and social problems that clearly call for coordinated responses, yet have no obvious, readymade solutions. Defenders of this approach must either distort such problems in ways that preclude the development of appropriate solutions, just to make assignments of responsibility intelligible, or else admit that unorganized groups bear no responsibility whatsoever for activating themselves. Neither option is acceptable.

One notable consequence of sidestepping systemic problems in general - and problems that existing institutions and practices are incapable of solving, in particular-is that the received approach ignores and renders irrelevant the epistemic agency and creativity of ordinary people. Suppose that the only problems loosely structured groups are collectively obligated to address are those for which clear collective action solutions have already, somehow, "come into focus." Oddly enough, we would never bear any responsibility for collectively analyzing especially complex, seemingly insoluble problems, even those we have a hand in creating and are harmed by; for cultivating each other's capacities to imagine new strategies; or for engaging in ongoing processes of collective learning, experimenting with, and revising those strategies over time. Some of us would probably find ourselves waiting around for others to dream up solutions, leaning on specialized institutions and authorities. Others would hope for sudden flashes of insight-flashes that are unlikely to ever come. Never calling upon one another to think for ourselves, our collective problem-solving capacities would likely atrophy from lack of use. Yet the problems would remain, growing worse all the while.

Instead of rendering the epistemic agency of ordinary people irrelevant, in the final section of this chapter I suggest that the production of new questions, ideas, and knowledge in and through collective struggle ought to be at the very center of future inquiry into collective responsibility. Rather than relying on thought experiments, I turn to a concrete case of people coming to each other's aid, exhibiting their collective brilliance under extraordinarily trying circumstances. I explore this case at some length, not to pump the reader's moral intuitions, or 
to defend an alternate set of criteria for collective liability, but in order bring to the fore certain questions about collective responsibility that would otherwise go unasked.

\subsection{Acting Together in the Midst of Disaster}

We must never forget these facts that made Hurricane Katrina a travesty: That climate change is creating unprecedented storms in size and intensity. Katrina was one of them. That ongoing ecological destruction in the name of profits has been perpetuated for more than a hundred years, including the destruction of wetlands and other natural barriers along the coastlines, allowing hurricanes to move further inland than ever before, in order to open up access to Gulf oil and commercial shipping routes. Next, it was that levees were built substandard by corruption and greed when contractors and some politicians knew they would never hold. And, finally, that the government response at all levels left thousands of people to die who had no means to evacuate due to health, age, and lack of funds, transportation, or connections. Individuals and families were trapped in their homes, on the streets, on their rooftops, and in their attics. Power reacted with brute force and criminalization of the people. It was criminal neglect. This was the latest in a long history of largely invisible disasters of neglect in these communities. To me, the levees became a symbol of the way that the corruption and arrogance of governments disregards the most vulnerable people.

(crow 2014: 4)

When Hurricane Katrina devastated communities across the Gulf Coast in the summer of 2005 , it became painfully clear to many people living in the U.S. that climate change was no longer some abstract or distant problem. As the above remarks from long-time community organizer scott crow suggest, the impacts of climate change ${ }^{9}$ are shaped by a variety of factorspsychological, social, and systemic - including inadequate preparation, corruption, arrogance, greed, and deeply ingrained patterns of indifference and neglect. When the levees surrounding New Orleans gave way to surging coastal waters, all the amenities upon which residents had come to rely abruptly vanished. Many houses were swept away or consumed by floodwaters, while others were left smoldering in flames amidst sparking power lines and leaky gas mains. Water, electrical, and telecommunications infrastructures were downed or disconnected. Flooded cars, busses, and streets rendered the usual modes of transportation unusable. Jobs were swiftly relocated, rendered irrelevant, or disappeared. Meanwhile, opportunistic landlords raised rents amidst growing real estate speculation. Developers and investors scooped up bundles of properties for a song, often holding buildings left vacant and in disrepair, banking on rising values to come. Charter schools swooped in to replace an underfunded public school system left further in disarray, saddled with dozens of crumbling buildings: rooves leaking, mold spreading, immersed in a toxic soup of floodwaters laced with gas, debris, and animal carcasses.

While thousands of New Orleanians were voluntarily evacuated by government agencies in the days following the storm, many others were forcefully displaced to disparate locations hundreds of miles away, often without any means of returning home. The several thousand others whom the federal government simply left behind to fend for themselves, or who were unable or refused to be evacuated from their homes, were faced with the enormous challenge of surviving in post-Katrina New Orleans. The difficult situations of many remaining residents were exacerbated by the fact that official channels of support proved grossly incapable of addressing emerging needs, particularly in historically underserviced neighborhoods. In several 
overwhelmingly poor, largely black communities, state-sponsored and professional relief was either entirely absent, or unhelpfully, insultingly present, answering to needs that didn't exist and setting up bureaucratic hurdles that prevented people from accessing needed services.

In his 2014 book, Black Flags and Windmills, crow offers an extensive account of why so many people were compelled to rush into New Orleans with "emergency hearts" (65), precisely when the federal government was struggling to evacuate everyone they could manage. In his own case, it was a longstanding friendship with Robert H. King, a former member of the Black Panther Party, that first moved crow to journey from his home in Austin, Texas. King, who was living in New Orleans when Katrina made landfall, lost contact with crow when the levees broke. With the streets flooding and news of a citywide lockdown spreading, crow grew increasingly worried. When an acquaintance proposed that the two go in search of King, crow "had to know if he was all right" (ibid. 8). "As a community organizer who cares about people no matter where they might be," recalls crow, "I felt that it was my responsibility to aid those in New Orleans who, already marginalized, now had total devastation added to their burden" (89). After making an initial, particularly jarring trip into the city by boat, the search team turned up no signs of their friend, returning to Austin deeply shaken by all they had encountered along the way.

Several days later, upon receiving a call for aid from Malik Rahim, crow decided to make a second trip to New Orleans. Taking another opportunity to search for King, he also intended to contribute to relief efforts organized by those with deep roots in the city. Rahim, a veteran community organizer and former Panther, had helped run free breakfast for children in two of the most poverty-stricken housing projects in New Orleans. Calling from his house in the predominantly black neighborhood of Algiers, Rahim reported to crow: "we got racist white vigilantes driving around in pickup trucks terrorizing black people on the street. It's very serious. We need supplies and support" (ibid. 46).

By the time crow arrived, Rahim and his neighbors, including native New Orleanian Sharon Johnson, had already been struggling to find ways to provide basic aid to one another. "There was no Red Cross, no FEMA," writes crow. "There were no other options" (ibid. 50). On September 5, 2005, the trio decided to form a collective based at Rahim's home in Algiers, calling themselves the "Common Ground Collective" in honor of their lost friend King. ${ }^{10}$ Within a week, the group grew to around fifty strong. Over the following months, its ranks swelled to several hundred, with mostly white, twenty-something, anarchist-oriented volunteers arriving from across the country. Common Ground was a community-initiated, all-volunteer organization with a mission "to provide short-term relief for victims of hurricane disasters in the Gulf Coast region, and long-term support in rebuilding the communities affected in the New Orleans area" (ibid. 229). Much of the group's work involved responding to seemingly intractable problems confronting those left behind, many of which were shaped, in part, by inept government and philanthropic responses. As crow recalls,

We were seeing, in real time, what slowly filtered out to become painfully apparent worldwide. The state was off balance and unresponsive. The entities within it were failing to grasp the developing issues. The Red Cross wasn't doing any better. They were raising billions of dollars while people were still suffering. For me, it was the closest thing to seeing those in Power lose their stranglehold of control. We interpreted this as an opportunity to create an autonomous space where residents could establish self-determination over their future, be treated with dignity and respect, and have access to basic services that hadn't existed in years, if ever. We would begin relief work, 
without reliance on or interference from the state or professional aid agencies. We would prefigure the civil society we would like to see in the future.

(ibid. 65)

I want to propose that an alternative approach to understanding collective responsibility can be assembled from the work of Common Ground-one that draws our attention to the collective accomplishments of ordinary people navigating impossibly difficult situations. ${ }^{11}$ This approach can be summarized in three recommendations for future inquiry, to which I now turn.

\subsubsection{Clear Paths or Paths Cleared?}

Characterizing Common Ground as a "revolutionary aid organization," crow recounts their first three years in Algiers as "a story of ordinary people compelled to act for justice in an extraordinary situation" (ibid. 59,4). Indeed, the collective's story is one of people joining forces to deal with problems that existing institutions and practices were not-and likely could notaddress, thus exhibiting their collective brilliance in action. As a guide to understanding collective responsibility, crow's retelling of the story teaches us to focus not on what other people ought to have known at a given instant, but on how those who came to each other's aid managed to generate new questions, ideas, and knowledge together, in and through collective struggle.

For instance, next to Algiers in the much smaller, wealthier, whiter neighborhood of Algiers Point, a racist white militia had surfaced in the wake of the storm. Militia members hung hostile, stigmatizing signs (e.g.,"You Loot, We Shoot") outside their homes and patrolled the streets of neighboring black communities in trucks, harassing and on several occasions, gunning down unarmed black men with impunity (Thompson 2008). "It was as if the dam of civil society that kept them from acting out their most racist tendencies had broken enough to allow their hatred to emerge," writes crow.

Local authorities, with their racist attitudes toward the communities they were supposed to protect, stood by and let this militia function. There were bullet-riddled bodies of black men in the street, including the one that we tried to get picked up for days while it continued to decompose.

(crow 2014: 51)

How would the collective and their neighbors protect themselves? Who would check these racist vigilantes, and how-with local law enforcement in complete disarray, at best, and passively or actively supporting racist terrorism, at worst? "In the stress of those days, I struggled to think through the unstable situation," writes crow (ibid. 59). Under circumstances unfamiliar to all involved, there was no dearth of clear solutions to the threat of racist violence left unpoliced. Nevertheless, drawing lessons from the community safety programs initiated by the Panthers in the late 1960s (see Newton 2009), and retailoring those experiments to suit a historically unique situation, members of Common Ground came up with the idea of setting up safety patrols, taking up a practice of community armed self-defense- a practice that crow notes was adopted reluctantly and as a last resort, following a series of violent confrontations (crow 2014: 55-58; cf. crow 2018). According to crow, “The presence of whites and blacks working together against the militia would later be cited by locals as one of the factors that helped ease tensions in that difficult time" (crow 2014: 54). "Self-defense opens up the possibility of changing the rules of engagement," he observes in retrospect. "It doesn't always make situations less violent, but it can help to balance the inequity of power" (ibid. 58). 
Taking up arms to discourage racist violence also helped remaining residents direct their collective energies to addressing the scarcity of basic amenities. After establishing a measure of security for themselves and their neighbors, on September 13 the collective came up with the idea of setting up a distribution center at Rahim's home. The plan was to gather supplies on regular out-of-town excursions while coordinating larger deliveries from abroad. Within a matter of weeks, Common Ground was able to make a wide variety of goods and services available to Algiers residents, operating the distribution center "from 7 a.m. until curfew, seven days a week" (ibid. 115). With the help of a team of street medics, the group also established a more permanent first aid station in a nearby mosque, which quickly evolved into the Common Ground Health Clinic. This clinic — one of three the collective would eventually set up-still operates to this day, having morphed into a non-profit organization by the same name.

Common Ground went on to give birth to a wide range of programs organically, out of necessity, attending keenly to evolving local problems and needs with an optimistic, creative outlook on the future. As crow puts it, "Our intentions were to create permanent and sustainable solutions with and for those who were the most affected," grounded in the practice of solidarity and, eventually, "mutual aid" (ibid. 103, 165). For example, in addition to providing protection from white militias and distributing basic amenities, members also fought for displaced residents' rights to return; provided legal aid and safe shelter for women; pressured police for accountability and supported prisoners' rights; prevented housing demolitions, partly by gutting and repairing structures; used available legal means and direct action tactics to halt evictions; worked together with neighborhood councils; and helped create long-term food security through small-scale agricultural projects (ibid. 165, Appendix). The collective included a team of street medics and, eventually, nurses and doctors. In addition to establishing clinics, members engaged in Latinx health care outreach; cleaned up garbage and toxic floodwaters along streets and in houses; provided soil and water testing; offered bioremediation services for soils damaged by toxic substances; made counselling and social work services available, as well as massage, acupuncture, and herbal remedies; constructed compost toilets for families dealing with plumbing problems and water shutoffs; and planted community gardens that brought people together growing food.

Unlike state and professional aid organizations, Common Ground refused to see those whom they were serving as faceless or helpless victims, insisting instead on treating their neighbors as "active participants in the struggle to make their lives better"- that is, as people who were coming together "to struggle for survival, justice, and self-determination" (ibid. 103, 60). Rather than establishing relations of dependence between long-time residents, on the one hand, and relief organizations staffed by out-of-towners, on the other, the collective worked to support those most directly affected by the storm in taking charge of their own lives; in collectively analyzing deeply rooted problems in the course of developing solutions; and in rebuilding their own communities in sustainable, self-determining ways. While it would not be unreasonable to suppose that organizations such as FEMA and the Red Cross ought to be best positioned to deliver aid, the types of solutions that seemed clearest to these groups were actually among the problems Algiers residents would be forced to confront.

\subsubsection{Inactive Groups or Groups in Action?}

The array of ideas and experiments Common Ground managed to generate in the midst of severe instability, uncertainty, and hostility is truly astounding. So is the amount of collective learning that took place over those years, which later nourished a variety of developing projects, including the Occupy Sandy relief efforts that surfaced in 2012 (see Lustig 2012; Moore \& 
Russell 2011). Second, then, I want to suggest that the story of Common Ground teaches us to focus not on particular, supposedly singularly significant moments of collective inaction, but on how such moments of astounding collective creativity emerge in the first place.

As the philosopher John P. Clark points out in his foreword to the second edition of Black Flags and Windmills, collective responses to overwhelmingly complex problems do not just materialize out of thin air, even when they seem like genuine miracles. They certainly are not the result of sudden flashes of insight, nor of clear blueprints for collective action studiously absorbed by groups of strangers. Rather, "such miracles have deep roots" (crow 2014: xviii). The moment of Common Ground's emergence was "the product of many small but powerful transformative moments," adds Clark (2014: xix), not only in the personal lives of its founders, but in the lives and afterlives of the broader social movements from which the collective drew inspiration, volunteers, and material support, and to whom its members continually looked for hard-won lessons.

Some of those histories of collective struggle helped shape the place and people of New Orleans, including many who became involved in Common Ground. Other layers were national and global in scope- particularly in the cases of the Spanish anarchists during the 1930s, the Black Panthers during the 1960s and 1970s, and the Zapatista Army for National Liberation (EZLN) from the 1980s onward, whose work was especially influential in the formation of Common Ground. "In each of these political tendencies, people rose up to create initiatives that addressed complex and interrelated problems," observes crow. “

They didn't follow prescribed blueprints for revolution; they reimagined and reconfigured them. When they made mistakes, they learned more about themselves and the evolving situations around them, so as to be more effective. They were motivated by the love of humanity that drives us to create something better in the face of cynicism and repression.

(2014: 72)

\subsubsection{Conditions for Collective Blame or Brilliance?}

Finally, the story of Common Ground teaches us to focus not on the conditions for collective liability and blame, but on how to create the conditions for more such moments of collective brilliance in the lives of more people..$^{12}$ These moments are clearly valuable, protecting people from impending harms while building towards more liveable futures. Moreover, we know that these moments have underlying conditions-not only in the initial hours and days when people find themselves thrown into states of emergency, but in the ongoing practices of mutual care and nurturance cultivated in their everyday lives, long before and after storms of various sorts.

I find crow's notion of the "emergency heart" useful in describing what motivates people to take up the responsibility we all share for making more such moments possible. Inspired by the words of Geronimo ji Jaga, the notion of the emergency heart encapsulates a deep feeling of love that "forms parts of the roots from which struggles grow" (ibid. 87). "Love drives what I call our emergency hearts to action and change in the face of repression and against all odds," writes crow. "The emergency heart is the feeling of empathy and compassion that motivates us to act now to end oppression and destruction. An emergency heart gets people into the streets to resist injustice and create something better" (ibid.).

Much as collective responses to overwhelmingly complex problems may seem to materialize out of thin air, the emergency heart may seem to beat for exceptional situations only, moving people to act in the now of disaster, in the midst of chaos and uncertainty. But there is another, 
more mundane sense in which the "state of emergency" is what arises between human beings whenever we find one another in assembly and set to work on assembling ourselves collectively. This everyday sense of emergency is, as Clark points out, "the normal condition of human beings in constant need of responsiveness to other human beings" (2014: xvii). Part of that shared need is a need to prepare each other to respond in situations where no clear and definitive responses are in the offing, and where no single portion of prior knowledge and skill will suffice. There are no sure-fire techniques for readying one another here, though there are plenty of past lessons from which to learn, and the story of Common Ground is but one worthwhile resource. Neither will there be any single, decisive moment where we collectively fail at the task of mutual preparation. As crow's retelling makes plain, it will take a good deal of patience and encouragement to sustain each other for the long haul-the creative patience of love in the midst of emergency.

\subsection{Conclusion}

In this chapter, I argued that the received way of thinking about responsibility for collective inaction is unhelpfully constraining. Not only does it exclude from consideration a range of systemic problems and crises that clearly call for coordinated responses, but in so doing, it ignores and renders irrelevant the epistemic agency and creativity of ordinary people. Perhaps these consequences would seem at least somewhat acceptable if the institutions and practices that have arisen over the past century were somehow capable of addressing each and every problem communities now face, and also equipped us to foresee and get out ahead of all possible complications down the line. As creatures in and of history, though, we should expect the emergence of new, more challenging situations in the wake of each solution proposed and implemented by fallible beings such as ourselves. Challenges such as these tend to encourage us to question those ways forward that have come to seem "clear" and "clearly favorable," to listen anew to and think differently with one another, and to rely on the collective resourcefulness and creativity of people in motion.

While exploring the work of Common Ground in post-Katrina New Orleans, I proposed an alternative approach to thinking about collective responsibility, expressed in summary form as three recommendations for future inquiry. When considering concrete cases of people acting together in response to seemingly intractable problems, I recommended that philosophers focus on how those who come to each other's aid manage to generate new questions, ideas, and knowledge together, in and through collective struggle; on how these moments of collective creativity emerge in the first place; and on how to create the conditions for more such moments in the lives of more people. The upshot of my proposal is that philosophical analyses of collective responsibility need to do justice to the existence of systemic problems, many of which cannot be solved by way of a single collective act, utilizing the epistemic resources and skills already at our disposal. Stories like that of Common Ground help us move beyond the limitations of the received view, which reduces collective responsibility to collective liability and, in so doing, narrows our focus to single, allegedly decisive moments of inaction, single-mindedly concerned with attributions of blame. Given that there are not always such singularly significant moments, particularly in the case of challenges both unforeseen and unforeseeable, it seems more important to start coming to grips with and acting upon our shared responsibility to develop each other's capacities for mutual responsiveness, preparation, and coordination in ongoing ways. As crow's words and work suggest, there is no special "now" when the emergency heart moves people into motion to create something better. 


\section{Michael D. Doan}

Whether and when we ought to hold ourselves and others accountable for our collective failure to take up this responsibility is no simple matter, particularly where stories of collective struggle are not well known or well studied. Perhaps by shifting our approach to thinking about collective responsibility, though, we might better enable one another to seize upon more opportunities for exhibiting collective brilliance in our everyday lives.

\section{Notes}

1 As Held explains, a "random collection" of individuals is a type of group distinguished by the fact that it has no decision-making procedure in place, and its members do not display much, if any, solidarity (Held 1970: 471).

2 The reasonable person standard is a legal fiction used to determine liability in criminal and tort cases. The term refers to a hypothetical person whose conduct exhibits average care, skill, and judgment. Thus, this person's conduct serves as a standard against which an actual person's conduct may appear negligent.

3 In an earlier paper (Doan 2016), I offer a critique of the epistemological assumptions undergirding this shared approach to thinking about collective inaction.

4 I understand epistemic agency in terms similar to Kristie Dotson, who focuses on "the ability to utilize persuasively shared epistemic resources within a given community of knowers in order to participate in knowledge production and, if required, the revision of those same resources" (Dotson 2014: 115).

5 I owe this formulation to Robin D. G. Kelley. As he points out, "Social movements generate new knowledge, new theories, new questions. The most radical ideas often grow out of concrete intellectual engagement with the problems of aggrieved populations confronting systems of oppression" (Kelley 2002: 8). With Kelley, I use the term collective struggle to refer to the collective efforts of aggrieved populations confronting systems of oppression and forcefully freeing themselves from systemic constraints.

6 I owe this formulation to Shea Howell.

7 I call it the knowledge condition because it implicitly references the cognitive states of the members of a random collection (Doan 2016: 6).

8 I draw inspiration here from Alexis Shotwell's thoughtful discussion of "constitutive impurity" (Shotwell 2016).

9 I understand climate change impacts in terms similar to Kyle Powys Whyte, who describes such effects as "arising based on the capacity of patterns of community relations to absorb local ecological alterations stemming from climate change," which may be more or less disruptive insofar as they can be absorbed by existing structures of organization without those structures needing to change (Whyte 2014: 601).

10 While giving a speech, King had once said: "If we as people are going to exploit anything it should be our commonness" (crow 2014: 96). King was eventually found, alongside his dog, Kenya. He told his friends: "I knew y'all would come" (ibid.).

11 I focus on the story of Common Ground not because the group's work is beyond criticism, but because it provides an illustrative example of people creating new cultural and economic practices together, through thousands upon thousands of collective acts.

12 While blame may sometimes be appropriate, its helpfulness in addressing the underlying problems is easily overstated. Partly for this reason, my work attends more to political than moral responsibility (Doan 2016).

\section{References}

“The Finale" (1998) Seinfeld. Season 9, episodes 23-4, NBC, May 14.

Clark, J.P. (2014) "Foreword to the Second Edition: In the Right Place, at the Right Time," in s. crow, Black Flags and Windmills: Hope, Anarchy, and the Common Ground Collective, 2nd ed., Oakland: AK Press: xvii-xxii.

Copp, D. (1991) “Responsibility for Collective Inaction,” Journal of Social Philosophy 22(2): 71-80.

crow, s. (2014) Black Flags and Windmills: Hope, Anarchy, and the Common Ground Collective, 2nd ed., Oakland: AK Press.

crow, s. (2018) Setting Sights: Histories and Reflections on Community Armed Self-Defense, Oakland: PM Press. 
Doan, M.D. (2016) "Responsibility for Collective Inaction and the Knowledge Condition," Social Epistemology 30(5-6): 532-554.

Dotson, K. (2014) “Conceptualizing Epistemic Oppression,” Social Epistemology 28(2): 115-138.

Held, V. (1970) "Can a Random Collection of Individuals Be Morally Responsible?" The Journal of Philosophy 67(14): 471-481.

Isaacs, T. (2011) Moral Responsibility in Collective Contexts, Oxford: Oxford University Press.

Kelley, R.D.G. (2002) Freedom Dreams: The Black Radical Imagination, Boston: Beacon Press.

Lustig, J. (2012) “Occupy Sandy's Street Medics Go Door-to-Door in Coney Island,” New York Magazine, November 6. http://nymag.com/daily/intelligencer/2012/11/occupy-sandy-goes-door-to-door-inconey-island.html.

May, L. (1990) "Collective Inaction and Shared Responsibility," Noûs 24(2): 269-277.

Moore, H. and Russell, J.K. (2011) Organizing Cools the Planet: Tools and Reflections to Navigate the Climate Crisis, Oakland: PM Press.

Newton, H.P. (2009) To Die for the People: The Writings of Huey P. Newton, edited by Toni Morrison, San Francisco: City Lights Books.

Petersson, B. (2008) "Collective Omissions and Responsibility," Philosophical Papers 37(2): 243-261.

Shotwell, A. (2016) Against Purity: Living Ethically in Compromised Times, Minneapolis: University of Minnesota Press.

Tännsjö, T. (2007) “The Myth of Innocence: On Collective Responsibility and Collective Punishment,” Philosophical Papers 36(2): 295-314.

Thompson, A.C. (2008) "Katrina's Hidden Race War," The Nation, December 17. Available at: www. thenation.com/article/katrinas-hidden-race-war/ (Accessed: 31 January 2019).

Whyte, K.P. (2014) "Indigenous Women, Climate Change Impacts, and Collective Action," Hypatia 29(3): 599-616.

Young, I.M. (2011) Responsibility for Justice, Oxford: Oxford University Press. 